\title{
Una nueva especie de Loeselia (Polemoniaceae) de CAMPEChe, MÉXICO
}

\author{
Celso Gutiérrez-Báez ${ }^{1,3}$ y Rodrigo Duno de Stefano² \\ ${ }^{1}$ Herbario UCAM, Centro de Investigaciones Históricas y Sociales. \\ Universidad Autónoma de Campeche. Av. Agustín Melgar s/n; entre Juan de la Barrera y calle 20, \\ Col. Buenavista, C.P. 24039, San Francisco de Campeche, Campeche, México \\ ${ }^{2}$ Herbario CICY, Centro de Investigación Científica de Yucatán, A.C., Calle 43, No. 130, \\ Col. Chuburná de Hidalgo, C.P. 97200, Mérida, Yucatán, México \\ ${ }_{3}^{3}$ Autor para correspondencia. Correo-e: cgutierr@uacam.mx
}

Resumen: Se describe e ilustra a Loeselia campechiana Gutiérrez-Báez \& R. Duno, una nueva especie de Polemoniaceae del estado de Campeche, México. Es la primera vez que se registra la familia para el estado. La nueva especie es muy rara y hasta la fecha se conoce de una localidad caracterizada por la presencia de una selva mediana subcaducifolia. Es morfológicamente similar a L. glandulosa (Cav.) G. Don, pero puede ser distinguida por tener brácteas más cortas, el tubo de la corola más corto y recto, los filamentos más cortos y también el estilo más corto.

Palabras clave: Loeselia campechiana, selva mediana subcaducifolia, Península de Yucatán.

\begin{abstract}
Loeselia campechiana Gutiérrez-Báez \& R. Duno (Polemoniaceae) a new species of Polemoniaceae, from the state of Campeche, México, is described and illustrated. It is the first time that the family is recorded in the state. The new species is rare, it is only know from one locality with a median semi-deciduous forest. Is morphologically similar to L. glandulosa (Cav.) G. Don, but can be distinguished by having shorter bracts; corolla tube shorter and straight, filaments and style shorter.
\end{abstract}

Key words: Loeselia campechiana, median semi-deciduous forest, Yucatan Peninsula.

E xisten 17 especies del género Loeselia L. (Polemoniaceae), todas crecen en México; sin embargo, seis de ellas (L. ciliata L., L. glandulosa (Cav.) G. Don, L. greggii S. Watson, L. mexicana (Lam.) Brand, L. pumila (M. Martens \& Galeotti) Walp. y L. ramosissima (M. Martens \& Galeotti) Walp.) se extienden más allá del territorio mexicano. El género se distribuye desde el suroeste de los Estados Unidos de América (Arizona y Texas), Centro América hasta Sur América (Colombia y Venezuela). El centro de diversidad parece ser la depresión del Balsas en el suroeste de México, donde se reportan ocho especies endémicas (Porter y Johnson, 2000; Porter y Steinmann, 2009).

El género Loeselia se caracteriza por ser hierbas anuales o perennes, arbustos pequeños, con hojas simples, alternas, a veces las inferiores opuestas y los márgenes aserrados a dentados. Las flores son solitarias o en agregados cimosos, con simetría bilateral y los estambres exertos (Nash, 1979; Porter y Steinmann, 2009; Short y Helgason, 2009).

En el 2005 se recolectó una planta que crecía en un claro de la selva mediana subcaducifolia, a unos $20 \mathrm{~km}$ al sureste de la ciudad de Campeche, esta planta resultó ser particularmente interesante, ya que pertenece a la familia Polemoniaceae, que nunca antes había sido reportada para la Provincia Biótica Península de Yucatán (Short y Helgason, 2009; Carnevali et al., 2010). Al tratar de determinar dicho material con la ayuda de los ejemplares de herbario (CICY, UADY, UCAM) y literatura especializada (Nash, 1979; Porter y Johnson, 2000; Porter y Steinmann, 2009; Rzedowski y Calderón 1995 ; Short y Helgason, 2009; Trópicos, 2014), se determinó que se trataba de una especie nueva para la ciencia. En este sentido, en el presente estudio se describe e ilustra a Loeselia campechiana, una especie hasta la fecha endémica y rara, para el estado de 


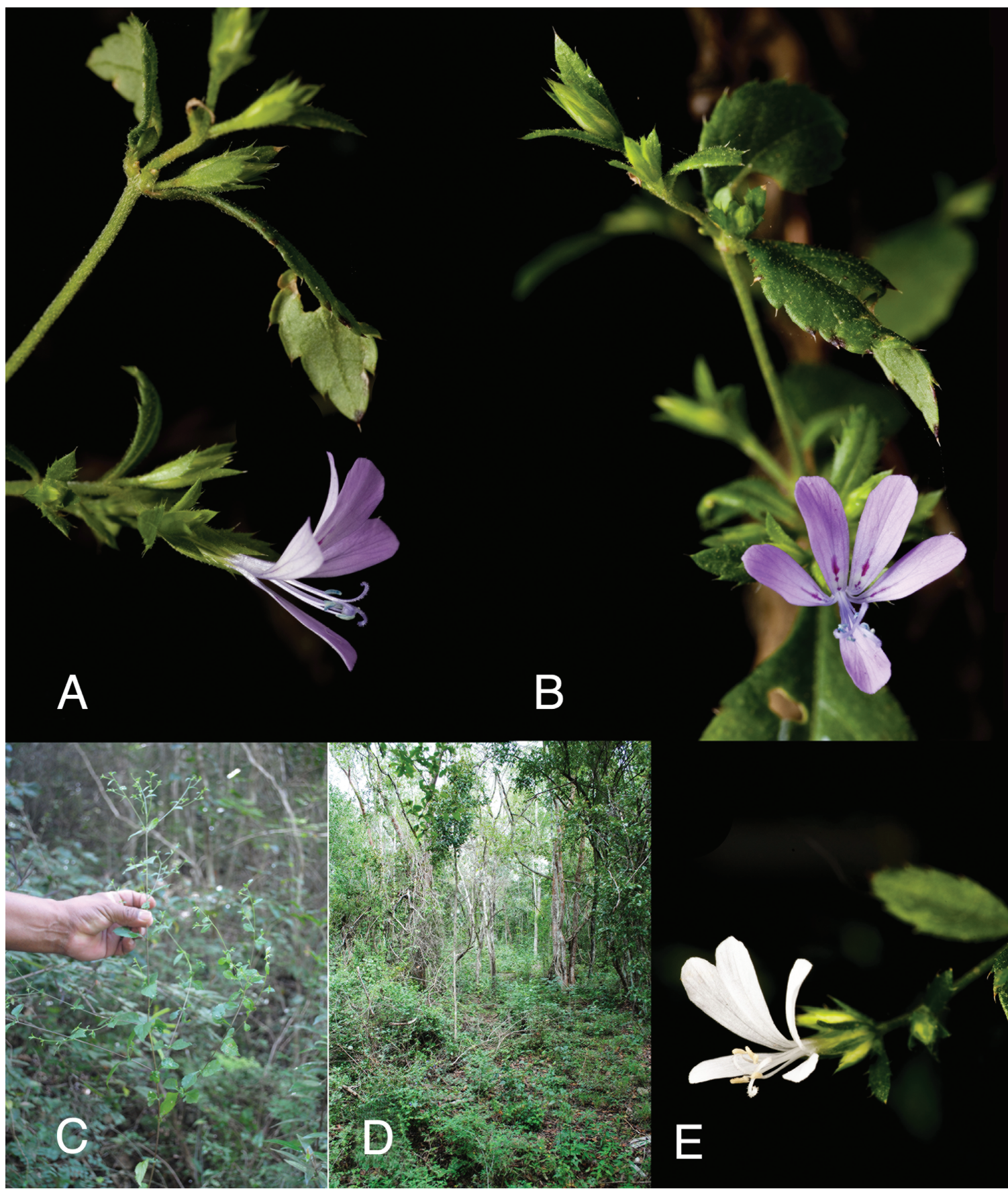

Figura 1. Imágenes de Loeselia campechiana, A) perfil, B) frente, C) recolecta, D) hábitat y E) flor color blanca. (Fotos: A y B tomadas por Gustavo Romero; C y D por R. Duno y E por Germán Carnevali).

Campeche y de la Provincia Biótica Península de Yucatán (Figura 3).

Loeselia campechiana Gutiérrez-Báez \& R. Duno, sp. nov. (Figuras 1,2).

Tipo: México, Campeche, municipio de Campeche, $2 \mathrm{~km}$ al SO de Mucuychakán, $19^{\circ} 40^{\prime} 14$ " N, 90²8'22" W, alt. $20 \mathrm{~m}$, suelo negro rocoso, secundaria, selva mediana subcaducifolia, 19/01/ 2012, C. Gutiérrez-Báez 10652 (Holo- tipo: UCAM; isotipos: CICY, ENCB, MEXU, MO, UADY, $\mathrm{XAL}$ ).

Herba annua, de 0.58- $0.80 \mathrm{~m}$ alta, foliis oppositis, ellípticolanceolatis, 30-40 mm longis, $15-20 \mathrm{~mm}$ latis, ad apicem subulatum, basi cuneatis. cimosa Inflorescentia; corolla 10 $\mathrm{mm}$ longis, $2 \mathrm{~mm}$ lata, pale roseus, pallidus lilac, purpurantibus maculis, antheris $2 \mathrm{~mm}$ longis, $0.5 \mathrm{~mm}$ latis. Semina 3 per loculo. 


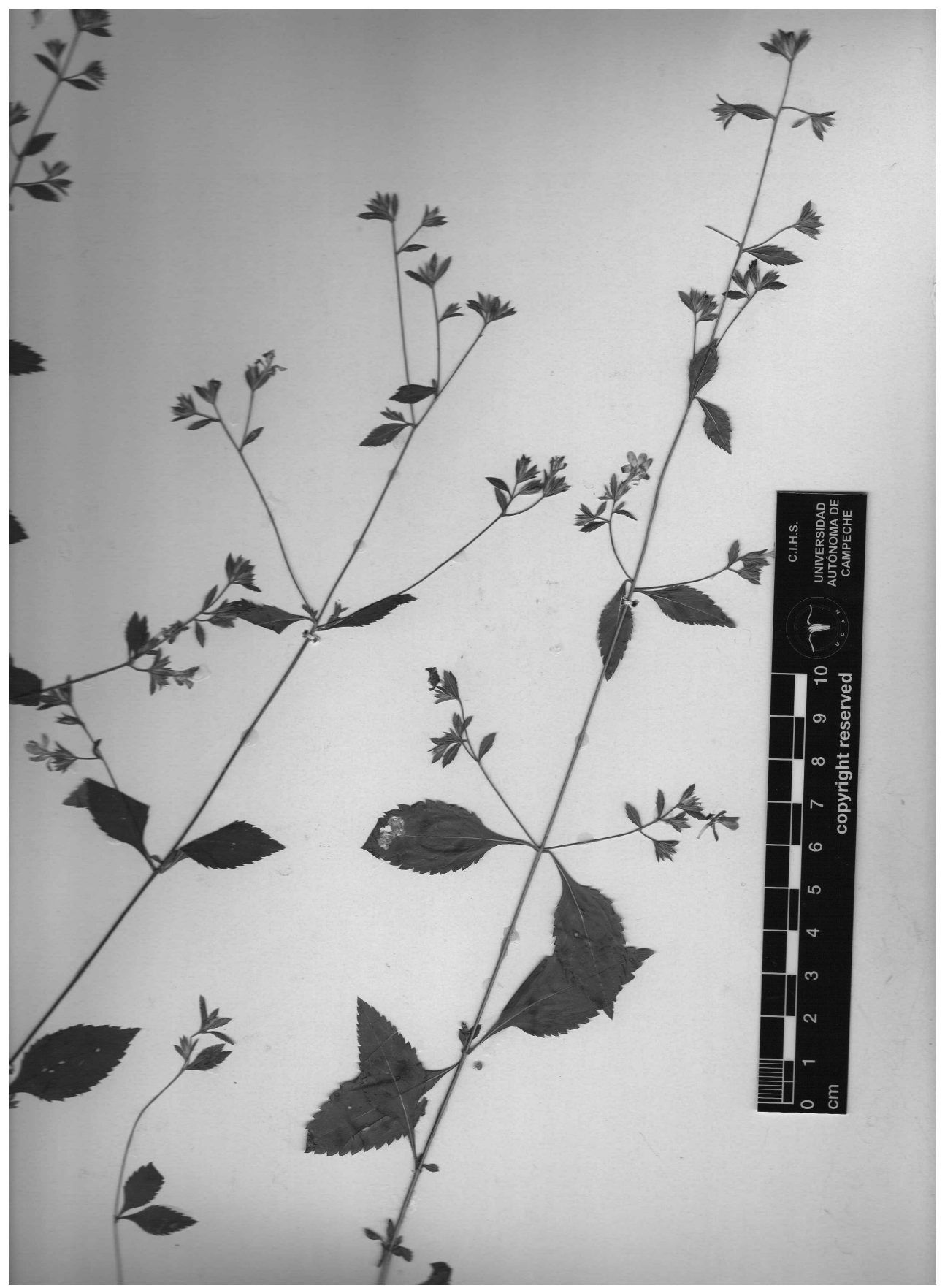

Figura 2. Ejemplar de herbario de Loeselia campechiana. Se muestra la disposición de las hojas e inflorescencias.

Hierba anual, tallo delgado, ramificado en la base, erecta, 0.58 a $0.80 \mathrm{~m}$ de alto, ramas jóvenes verdes, glandularpubescentes. Hojas subsésiles, opuestas, la lámina elípticolanceolada, 30-40 mm de largo, 15-20 mm de ancho, ápice subulado, base decurrente, margen aserrado, de color verde brillante, glandular pubescente en ambas superficies, las hojas caulinares superiores se reducen en tamaño, lanceoladas, 10-20 mm de largo, $8 \mathrm{~mm}$ de ancho, ápice acuminado, margen aserrado, glandular pubescente. Inflorescencias cimo- sas, con muy pocas flores, pedúnculo $2-5 \mathrm{~cm}$ de $1 \operatorname{argo}, 1 \mathrm{~mm}$ de ancho en las axilas de las hojas de las ramas laterales, flores subtendidas por 4 brácteas exteriores, lanceoladas, de $4 \mathrm{~mm}$ de largo, $1.5 \mathrm{~mm}$ de ancho, generalmente denticuladas, clorofílicas, verdosas, glabrescentes; brácteas interiores 5, más o menos blanco-hialinas, de $4 \mathrm{~mm}$ de largo, $1.5 \mathrm{~mm}$ de ancho, glabrescentes. Cáliz subcilíndrico, escarioso, 4-5 $\mathrm{mm}$ de largo, $0.5 \mathrm{~mm}$ de ancho, hialino, los lóbulos acuminados, 2 a $3 \mathrm{~mm}$ de largo, $1 \mathrm{~mm}$ de ancho, enteros, triangu- 
Cuadro 1. Comparación morfológica, ecológica de Loeselia campechiana y L. glandulosa.

\begin{tabular}{lll}
\hline & Loeselia campechiana & Loeselia glandulosa \\
\hline Altitud(m s.n.m.) & 20 & $300-2300$ \\
Tipo de vegetación & Selva mediana subcaducifolia & $\begin{array}{l}\text { Bosque de pino-encino y bosque mesófilo } \\
\text { de montaña }\end{array}$ \\
$\begin{array}{l}\text { Longitud de la bráctea externa }(\mathrm{mm}) \\
\text { y pubescencia }\end{array}$ & 4 , glabrescente & 7-10, puberulenta \\
$\begin{array}{l}\text { Longitud de la bráctea interna }(\mathrm{mm}) \\
\text { y pubescencia }\end{array}$ & 4 , glabrescente & $6-7$, puberulenta \\
Características de los lóbulos de la corola & parcialmente geniculados (4 superiores) & geniculados (3 superiores) y rectos (2 inferiores) \\
Longitud del tubo $(\mathrm{mm})$ y forma & y rectos (1 inferior) & $6-7$, geniculado \\
Forma del filamento & 4, recto & geniculado \\
Tamaño de la antera $(\mathrm{mm})$ & recto & $0.8-1.1$ \\
Longitud del estilo $(\mathrm{mm})$ y forma & $1.5-2$ & 14, parcialmente geniculado \\
Número de semilla por lóculo & 8, recto & $1-4$ \\
Largo de la semilla $(\mathrm{mm})$ & 3 & 2 \\
\hline
\end{tabular}

lares agudos, con una arista terminal, tubo del cáliz, $4 \mathrm{~mm}$ de largo, $1.5 \mathrm{~mm}$ de diámetro, glabro. Corola hipocrateriforme, rosácea, lila pálido, con manchas púrpuras en la base o completamente blanca, lóbulos (parcialmente geniculados los superiores y rectos los inferiores), espatulados, ápice obtuso, $10 \mathrm{~mm}$ de largo, $2 \mathrm{~mm}$ de ancho, glandulares, glabros, tubo estrecho, $4 \mathrm{~mm}$ de largo, $1 \mathrm{~mm}$ de ancho, recto, glandular, glabro; cinco filamentos rectos, $5 \mathrm{~mm}$ por encima del tubo; antera 1.5-2 $\mathrm{mm}$ de largo, $0.5 \mathrm{~mm}$ de ancho, color morada. Ovario piriforme, $1.5 \mathrm{~mm}$ de altura, $1 \mathrm{~mm}$ de ancho, estilo $8.5 \mathrm{~mm}$ de largo, recto, lóbulo del estigma $1 \mathrm{~mm}$ de largo. Cápsula elipsoide, $4 \mathrm{~mm}$ largo, $1.5 \mathrm{~mm}$ de ancho. Semillas 3 por lóculo, $1.5 \mathrm{~mm}$ de largo, aplanadas ovadas.

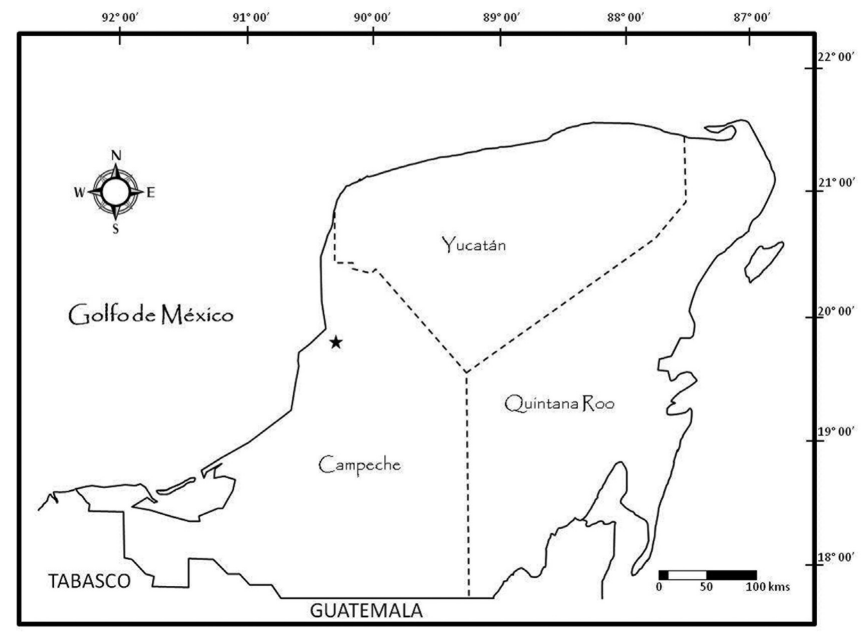

Figura 3. Sitio de muestreo de Loeselia campechiana en el estado de Campeche $(*)$.
Ecología. Loeselia campechiana es conocida únicamente en una pequeña localidad del estado de Campeche, dominado por un paisaje de lomerío, con suelo rocoso y a $20 \mathrm{~m}$ de altura sobre el nivel del mar. En el sitio se desarrolla una selva mediana subcaducifolia.

Entre las especies que conforman la selva de esta localidad están las siguientes: Alvaradoa amorphoides Liebm. ssp. amorphoides, Bunchosia swartziana Griseb., Byrsonima bucidifolia Standl., Chamaedorea zeifrizii Burret, Coccoloba barbadensis Jacq., Coursetia caribaea (Jacq.) Lavin, Croton hirtus L.'Her., Cydista diversifolia (Kunth) Miers, Diospyros yatesiana Standl., Guettarda combsii Urb., Guettarda gaumeri Standl., Hampea trilobata Standl., Hibiscus poeppigii (Spreng.) Garcke, Hybanthus yucatanensis Millsp., Ipomoea crinicalyx S. Moore, Ipomoea heterodoxa Standl. \& Steyerm., Ipomoea tuxtlensis House, Laetia thamnia L., Lonchocarpus rugosus Benth, Malpighia glabra L., Metopium brownei (Jacq.)Urb., Neea psychotrioides Donn.Sm., Ocimum campechianum Mill., Pachyrrhizus erosus (L.) Urb., Psidium sartorianum (O. Berg) Nied., Randia aculeata L., Randia longiloba Hemsl., Samyda yucatanensis Standl., Sapranthus campechianus (Kunth) Standl., Schwenckia americana L., Scleria lithosperma (L.) Sw., Selaginella sertata Spring, Simarouba amara Aubl., Tabernaemontana amygdalifolia Jacq. y Tillandsia schiedeana Steud.

Fenología. La floración ocurre entre enero-febrero y la fructificación en marzo (la parte más seca del año).

Etimología. El epíteto específico del latín es dedicado al estado de Campeche.

Loeselia campechiana parece estar estrechamente relacionada a Loeselia glandulosa, pero se distingue por las características morfológicas y ecológicas presentadas en el cuadro 1. 
Especímenes adicionales examinados. México, Campeche: Municipio de Campeche, 2 km SO de Mucuychakán, 12/03/ 2005, 1940'14" N, 90²8'22" W, alt. 20 m, C. Gutiérrez-Báez 8490 (UCAM), misma localidad, 8/01/2006, 8992 (MEXU, UCAM), 12/01/2012, 10648 (UCAM), 19/01/2013, 10847 (MEXU, UADY, UCAM, XAL); misma localidad, 31/01/2014, R. Duno de Stefano \& C. GutiérrezBáez 2549 (CICY).

\section{Agradecimientos}

Al Dr. William J. Folan y Lynda Florey por su constante apoyo, al Dr. Sergio Avendaño Reyes por proporcionarnos imágenes de Loeselia del herbario XAL, al Lic. Juan José Cosgaya Medina por la elaboración del mapa, al Dr. Gustavo Romero, Dr. Germán Carnevali y al M. en C. Jesús Vargas Soriano por las fotos tomadas del ejemplar y a los compañeros de trabajo M. en C. Pedro Zamora Crescencio y Nury Méndez Jiménez.

Recibido: 4 de junio de 2014

Aceptado: 27 de abril de 2015

\section{Literatura citada}

Carnevali F. C. G., Tapia-Muñoz J. L., Duno de Stefano R. y Ramírez M. I. 2010. Flora Ilustrada de la Península de Yucatán: Listado florístico. Centro de Investigación Científica de Yucatán, A.C., Mérida, Yucatán, México.

Nash D. L. 1979. Polemoniaceae. Flora de Veracruz. 7:1-27.

Porter J. M. y Johnson L. A. 2000. A phylogenetic classification of Polemoniaceae . Aliso 19: 55-91.

Porter J. M. y Steinmann V. W. 2009. Two New Loeselia (Polemoniaceae) Species from Michoacán, Mexico. Systematic Botany, 34(4):730-736.

Rzedowski J. y Calderón R. G. 1995. Familia Polemoniaceae. Flora del bajío y de Regiones Adyacentes 33:1-41.

Short M. J. y Helgason T. 2009. Polemoniaceae. En: Davidse G., Sousa S. M., Knapp S. y Chiang F. Eds. Flora Mesoamericana. Vol. 4, Cucurbitaceae a Polemoniaceae, pp.768-772, Universidad Nacional Autónoma de México, Instituto de Biología, Missouri Botanical Garden, The Natural History Museum, Saint Louis, Missouri.

Tropicos.org. 2014. Missouri Botanical Garden. <http://www.tropicos.org> (consultado14 de marzo 2014). 